\title{
The seasonal characteristics of the breeze circulation at a coastal Mediterranean site in South Italy
}

\author{
S. Federico ${ }^{1,2}$, L. Pasqualoni ${ }^{3}$, A. M. Sempreviva ${ }^{1,4}$, L. De Leo ${ }^{2}$, E. Avolio ${ }^{2}$, C. R. Calidonna ${ }^{1}$, and \\ C. Bellecci ${ }^{3,2}$ \\ ${ }^{1}$ Institute of Atmospheric Sciences and Climate, Italian National Research Council (ISAC-CNR), \\ Section of Lamezia Terme, Italy \\ ${ }^{2}$ CRATI Scrl, Rende, Italy \\ ${ }^{3}$ Engineering Department, University of Rome “Tor Vergata”, Italy \\ ${ }^{4}$ Wind Energy Department, Risoe-Danish Technical University, Roskilde, Denmark
}

Received: 10 February 2010 - Revised: 16 April 2010 - Accepted: 19 April 2010 - Published: 27 April 2010

\begin{abstract}
We present a study on the characteristics of the sea breeze flow at a coastal site located in the centre of the Mediterranean basin at the southern tip of Italy. This study is finalized to add new data on breeze circulations over a narrow peninsula and present a unique experimental coastal site at about $600 \mathrm{~m}$ from the coastline in a flat open area at the foot of a mountain chain located in a region of complex orography. We study the seasonal behaviour of the sea-land breeze circulation by analysing two years of hourly data of wind speed and direction, temperature, radiation and relative humidity from a surface meteorological station, eighteen-months data from a wind profiler, and two-year data from the ECMWF analysis.

Results show that breezes dominate the local circulation and play a major role for the local climate. They are modulated by the season, through the sea-land temperature difference and the large-scale flow. The large-scale forcing acts in phase with the diurnal breeze and opposes the nocturnal breeze.

In summer, the daytime difference between the land surface temperature and the SST (Sea Surface Temperature) reaches its maximum, while the nigh-time difference has its minimum. This causes a strong, frequent and intense diurnal breeze and a weak nocturnal breeze.

In winter and fall the nocturnal difference between the sea and land surface temperature reaches a maximum value, while the diurnal difference is at its minimum value. This causes a strong, frequent and intense nocturnal breeze despite of the large-scale forcing that is usually opposed to local-scale flow.
\end{abstract}

\section{Introduction}

Modeling the adjustment of the onshore flow inland from the coastal discontinuity in meso-scale models is still a challenge being limited by the resolution of the model grid and by the availability of comprehensive databases. A special case of flow adjustment happens during the development of the sea and land breeze system that is a meso-scale feature also involving offshore coastal areas. Sea breeze is developing on fine weather days due to the sea-land temperature difference that produces a pressure gradient between the sea and the land that forces an onshore flow. The opposite circulation,

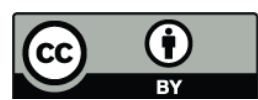

Correspondence to: S. Federico

(s.federico@isac.cnr.it) occurring at night, is called land breeze, if the temperature gradient between sea and land is reversed. The observed seabreeze intensity that can reach $10 \mathrm{~ms}^{-1}$ (Pielke, 2002) varies depending on several factors such as large-scale winds, atmospheric static stability, cloud coverage, land use etc. The land breeze is a shallower and weaker phenomenon than the sea breeze because the planetary boundary layer (PBL) over land is stably stratified at night. Defant (1951) presents an excellent qualitative description of sea and land breeze development in absence of large-scale wind.

In a mountainous region, local wind patterns can develop because of the differential heating between the ground surface and the free atmosphere at the same elevation some distance away. A larger diurnal temperature variation usually occurs at the ground exposed to the sun, so that, at daytime, elevated terrain becomes a heat source, while at the night it 


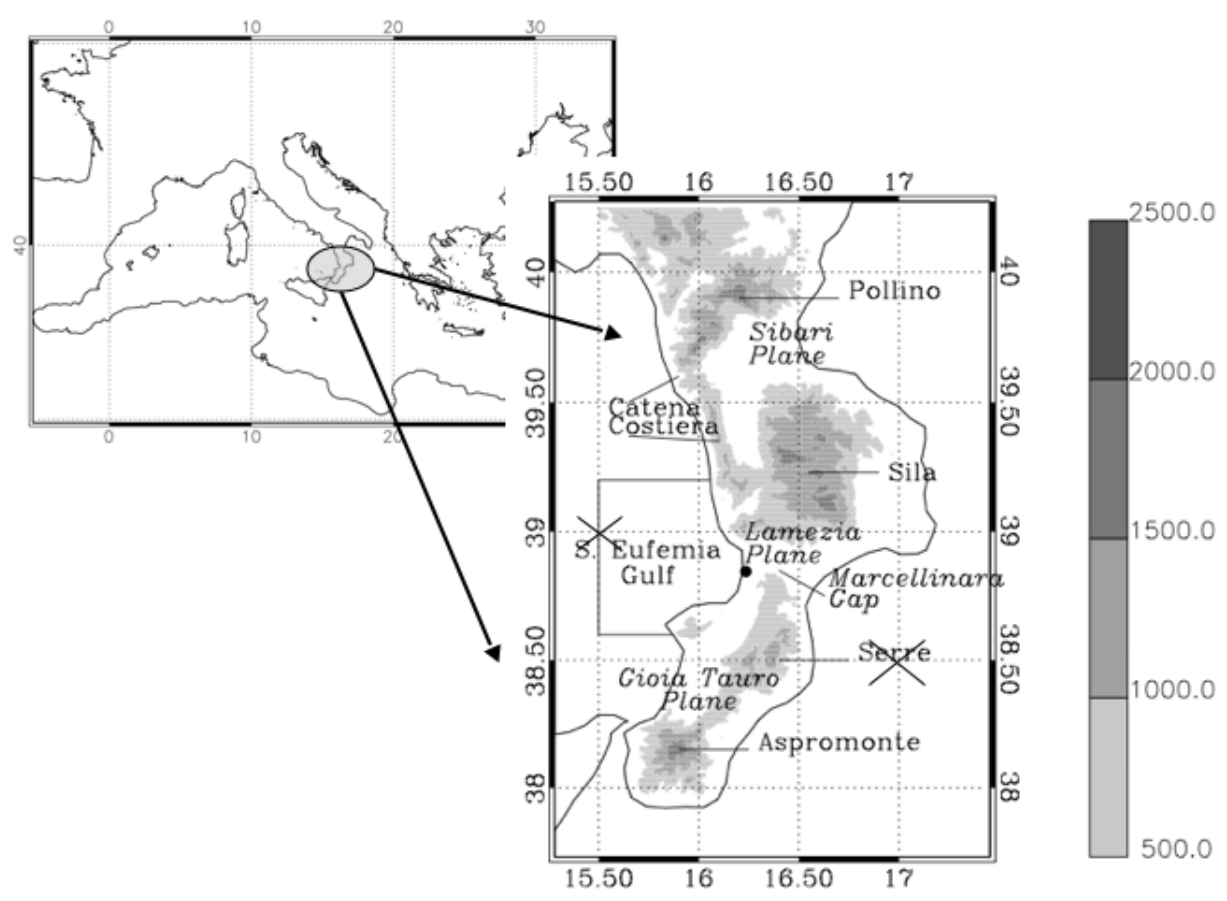

Figure 1. Calabria region in the central Mediterranean. Left: topography ( $\mathrm{m}$, gray shading) with topographical features cited into the text. The black dot shows the location of the experimental field. Crosses denote grid points considered in Table 2.

is an elevated heat sink. Soil temperature differences might intensify the temperature gradient between two atmospheric columns above elevated peaks and valleys. As a consequence of the temperature gradient generated, during fair weather days an upslope flow (anabatic winds) develops at daytime while, while down-slope (katabatic) winds develop during nigh time.

Because of the specificity of the breeze circulation at a particular site, several papers and books can be found in the bibliography on sea breeze and local winds, some of them reported in Simpson (1994) and Pielke (2002).

This study investigates local circulations at a site in the Central Mediterranean at the west coast of the narrow Calabria peninsula (Fig. 1), the southernmost tip of Italy. Calabria extends for $300 \mathrm{~km}$ between $38^{\circ}$ and $40^{\circ}$ latitude north and between $15^{\circ} 30^{\prime}$ and $17^{\circ} 15^{\prime}$ longitude east. The region is bounded by the Tyrrhenian Sea (west) and by the Ionian Sea (east and south). The Apennines Mountains run north-south and are characterized by five main topographical features reaching 1500-2000 m elevations: Pollino, Catena Costiera, Sila, Serre and Aspromonte. The average width of the region is about $50 \mathrm{~km}$ in the west-east direction.

The physical characteristics of the region, i.e. the presence of elevated mountain range along the peninsula in a symmetric position between the Tyrrhenian and the Ionian seas, provide a rather unique condition for breeze development and convergence. Sea breeze and land breeze might act in phase with upslope and down-slope winds to determine stronger and more persistent breeze system. Federico et al. (2000,
2003), using a theoretical and modelling approach, studied the relative role of the sea-land and mountain-valley contrasts for the local thermal convergence pattern over an idealized mountainous peninsula. They showed that the topography plays a fundamental role in determining the meso-scale flows. The presence of mountains highly enhances breezes and, for an idealized peninsula with the aspect (i.e. west-east width and mountains height) of Calabria, the energetic contribution of the mountain-valley contrast is larger than the sea-land contrast. Finally, the limited width of the peninsula, allows two situations (i) the upslope - down-slope breeze and the sea-land breeze merge (ii) the Tyrrhenian and the Ionian Sea breeze can converge at the centre of the peninsula creating cloud formation and very local precipitations (De Leo et al., 2008).

There is another important factor that favours the breeze development in Calabria: the Mediterranean climate. Calabria geographical position is at the centre of the Mediterranean where the atmospheric pressure field can determine calm synoptic conditions (Trigo, 1999, 2002; Bolle, 2003), especially in summer and fall (Conte et al., 1989; Colacino et al., 1990; Piervitali et al., 1999; Federico et al., 2009). These conditions favour the breeze development. The favourable conditions for the breeze development in the Mediterranean have been discussed and reported in several papers (Doran (1979) for Israel; Kallos et al. (1993) for Greece; Caccia et al. (2004) for France; and Mastrantonio et al. (2008) for Italy). 
Table 1. Instruments, parameters measured and working periods.

\begin{tabular}{|c|c|c|}
\hline Instrument & Data & Operational period \\
\hline Surface Meteorological station & $\begin{array}{l}\text { Wind speed and direction; Tempera- } \\
\text { ture; Global radiation; Precipitation; } \\
\text { Relative Humidity; Pressure. }\end{array}$ & $\begin{array}{l}\text { Permanently installed. } \\
\text { From } 1 \text { January } 2007 \text { to } \\
31 \text { December } 2008 .\end{array}$ \\
\hline RADAR WP & $\begin{array}{l}\text { Wind vertical profiles of the three wind } \\
\text { components. }\end{array}$ & $\begin{array}{l}\text { Permanently installed. } \\
\text { From } 1 \text { June } 2008 .\end{array}$ \\
\hline
\end{tabular}

While previous studies over Calabria were based on modelling the breezes, this paper focuses on experimental data collected at the Joint CRATI/ISAC-CNR site of Lamezia Terme, at the centre of the Tyrrhenian coast (Fig. 1) and at the end of the only west-east valley (the Marcellinara gap) connecting the Tyrrhenian and Ionian seas.

The paper is organized as follows: in Sect. 2, we shortly introduce the instrumental setup and the available database; in Sect. 3, we show the results and we then provide final remarks in Sect. 4.

\section{Measurements}

In this study, we use observations from different instruments operating at the experimental site located at $8 \mathrm{~m}$ a.s.l. and at $600 \mathrm{~m}$ from the coast http://www.crati.it/altre_attivita_crati/ Lamezia_experimental_field_web.pdf. A list and the operation time for each instrument are shown in Table 1.

\subsection{Surface station}

A surface meteorological station operates since June 2006 measuring temperature $T$, wind speed $U$, and direction DIR at $10 \mathrm{~m}$ a.g.l.; precipitation $\mathrm{Pr}$, relative humidity $H$, atmospheric pressure $P$, and global solar radiation Rad are collected at the height of $2 \mathrm{~m}$; soil temperature has been measured at $10 \mathrm{~cm}$ depth (from 1 January 2008). Data are available every $15 \mathrm{~min}$ but, in this paper, we use hourly averages. Missing data, caused by instruments maintenance, for the two years are less than 5\%. The range value of the wind speed measured by the anemometer installed at the site is $0.5 \mathrm{~ms}^{-1}-55 \mathrm{~ms}^{-1}$. Velocities less than $0.5 \mathrm{~ms}^{-1}$ (wind calm) with $f=12 \%$ have been discarded.

\subsection{Radar wind profiler}

A radar wind profiler is operating at the experimental site since 1 June 2008. The radar sounds the lower troposphere, usually up to $3 \mathrm{~km}$, and measures the horizontal and vertical wind components thanks to one vertical and two oblique beams slanted at off-zenith angle of $15.5^{\circ}$. The operating frequency is $1290 \mathrm{MHz}$ (about $23 \mathrm{~cm}$ wavelength). Returned echoes are due to air masses refractive index fluctuation advected by the wind. The dataset consists of $30 \mathrm{~min}$ average of the wind components. The vertical resolution is $100 \mathrm{~m}$, the minimum range gate is $150 \mathrm{~m}$ and the vertical range is $2-5 \mathrm{~km}$ depending on atmospheric conditions. Accuracy of wind measurements is $<1 \mathrm{~ms}^{-1}$ for the horizontal wind components, $0.5 \mathrm{~m}^{-1}$ for the vertical component and less than $10^{\circ}$ for the direction. Here, we use one-year data from June 2008 to May 2009.

\subsection{Sea Surface Temperature (satellite observations)}

The Tyrrhenian Sea Surface skin Temperature (SST), within the S. Eufemia Gulf (Fig. 1), facing the experimental site, was estimated using data disseminated by EUMETSAT Ocean \& Sea Ice Satellite Application Facility (www.osi-saf. org). The original dataset consists of 12-hourly means centred on 00:00 and 12:00 h UTC with a horizontal resolution of about $10 \mathrm{~km}$ for 2007 and 2008. A general overview of the dataset, the algorithms and processing scheme is given by O\&SI SAF (2006). SST is computed by space averaging the pixel values inside the square area in Fig. 1, representative of the portion the sea relevant for the development of the local circulation. It should be emphasized that the Rossby radius, i.e. the e-folding distance of the sea breeze from the coastline, is about $100 \mathrm{~km}$ for the latitude and static stability typical of Calabria peninsula (Abe and Yoshida, 1982). Because the width of Calabria is less than $100 \mathrm{~km}$, the sea-land and mountain-valley breezes from both sides of the peninsula collide and an effective Rossby radius is established, which is about $50 \mathrm{~km}$ for Calabria (Federico et al., 2000). The sealand and upslope-downslope breezes have and extension of one effective Rossby radius and the width of the sea in front of Lamezia Terme considered in our analysis (Fig. 1) is about $50 \mathrm{~km}$.

Data from O\&SI SAF are flagged according to the quality of the estimated SST and of the information on the processing conditions. The pixels where the SST is calculated are labelled on a five level scale: 5 = "excellent", 4 = "good", 3 = "acceptable", 2 = "bad", 1 = "erroneous" depending on pixel distance from clouds, SST climatology, sun glint effect etc. The "erroneous" confidence level may be attributed to a parameter missing due to a failure of the algorithm or present but with a very low level of confidence. For this study, we only used pixels with a confidence level greater than 3 . 


\section{Results}

\subsection{Breeze climatology for 2007-2008}

Figure $2 \mathrm{a}$ shows the wind rose recorded at the surface station for the period of two complete years i.e. 2007-2008. Winds blow from two main directions: W-WSW and NE-ENE. These directions account for $71 \%$ of the observed winds and their occurrence is similar, which gives to the wind rose a quite symmetrical aspect with respect to the axes intersection: $34 \%$ from NE-ENE, 37\% from W-WSW. Wind speeds are low and the occurrence of $U<6 \mathrm{~ms}^{-1}$ represents more than $90 \%$. The threshold $6 \mathrm{~ms}^{-1}$ was chosen after a subjective inspection of measurements from different sources (including ECMWF surface and $850 \mathrm{hPa}$ analyses). In particular, it was evident that surface winds larger than $6 \mathrm{~ms}^{-1}$ are attained when moderate-high surface pressure gradient are present over the area. On these days, the breeze circulation does not develop and the local circulation is dominated by the large-scale wind.

In order to study the coastal flow regime, it is necessary to analyse the data above the breeze circulation. Figure $2 b$ shows the wind rose at $850 \mathrm{hPa}$, for the same period as in Fig. 2a (from 1 January 2007 to 31 December 2008), derived from the ECMWF (European Centre for Medium Weather range Forecast) operational analysis at $850 \mathrm{hPa}$ (Uppala et al., 2005). These data, available every $6 \mathrm{~h}$, are representative of the large-scale circulation above the breeze re-circulation system because about $45 \%$ of the winds come from the NW sector. Beside the expected higher wind speed at $850 \mathrm{hPa}$, the comparison between Fig. $2 \mathrm{a}$ and $\mathrm{b}$ reveals the importance of local circulations at the surface because: a) the directions in Fig. 2a are well focused (W-WSW and NE-ENE) while at $850 \mathrm{hPa}$ the wind direction range is more spread; b) the NEENE components that might account form the channelled wind by the Marcellinara gap and the land breeze, are much more frequent at the surface $34 \%$ and $7 \%$ at the surface and at $850 \mathrm{hPa}$ respectively); and c) the W-WSW directions frequency at the surface is twice that at $850 \mathrm{hPa}(37 \%$ and $18 \%$ respectively).

To further confirm the difference between the circulation at the surface and at levels above the breeze, we show (Fig. 2c) the wind rose recorded by the wind profiler at $1.7 \mathrm{~km}$ a.g.l. (roughly $800 \mathrm{hPa}$ ) from 1 June 2008 to 31 May 2009. The comparison between Fig. $2 \mathrm{~b}$ and $\mathrm{c}$ shows the similarity of the wind distribution at high level from model and data and their difference with the surface wind distribution in Fig. 2a. The discrepancy between the wind distribution in Fig. $2 b$ and $\mathrm{c}$ are due to the not overlapping periods taken into consideration for the analysis of the data from the ECMWF model and the wind profiler. The analysis of data from an overlapping time window would have been advisable for conclusively supporting our discussion. However, isolating a complete year of the wind profiler data has allowed to take into consideration the wind seasonal variation, which has been

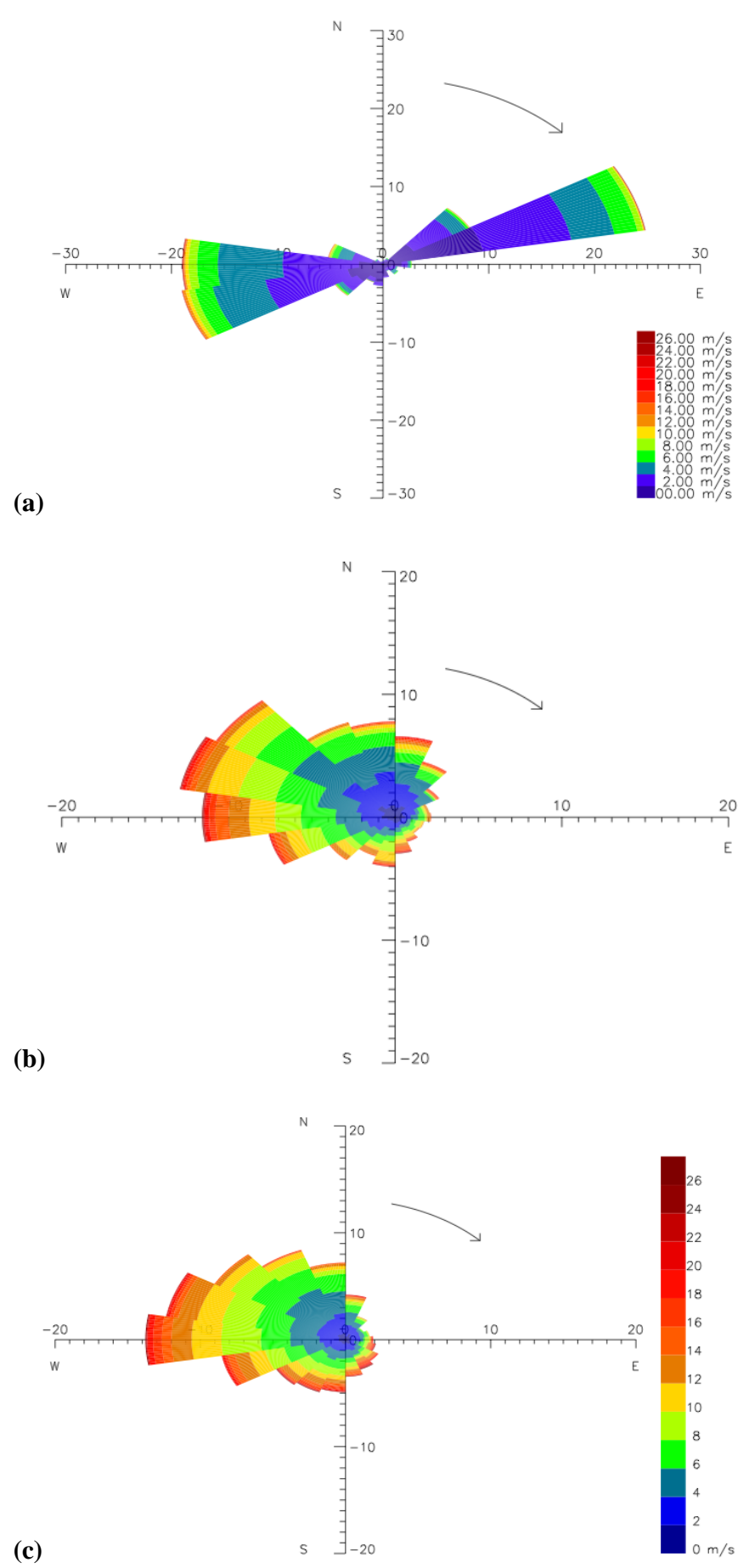

Figure 2. (a) Wind rose recorded at the Lamezia Terme surface station from 1 January 2007 to 31 December 2008. Color shading shows the wind intensity $\left(\mathrm{ms}^{-1}\right)$. (b) as in (a) for ECMWF analysis at $850 \mathrm{hPa}$ from 1 January 2007 to 31 December 2008. (c) Wind rose recorded $1700 \mathrm{~m}$ a.g.l. by the UHF wind profiler form 1 June 2008 to 31 May 2009. 


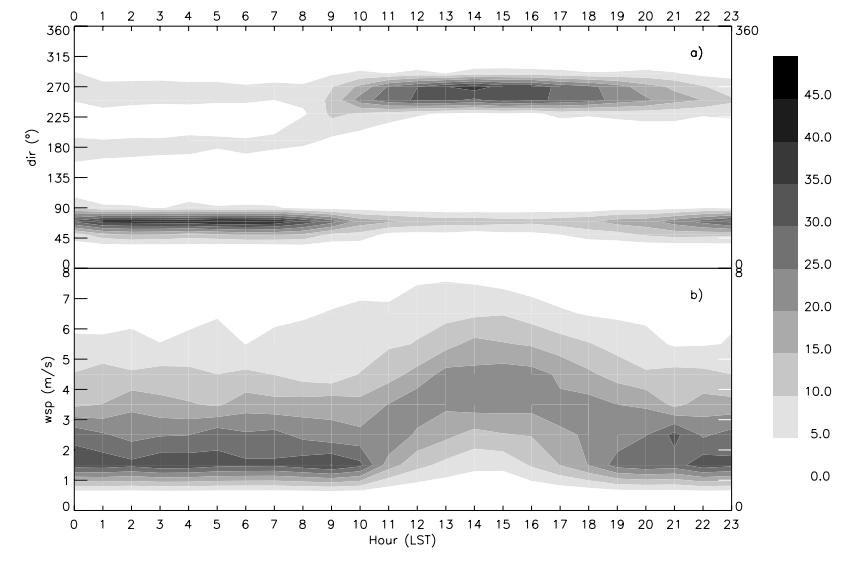

Figure 3. (a) Frequency of wind direction as a function of day hours recorded at the Lamezia Terme surface station for 2007-2008. Grey shading shows the frequency of occurrence (\%). (b) as in (a) but for the wind speed. LST $=\mathrm{UTC}+1 \mathrm{~h}$.

shown to have a smaller inter-annual variation from the analysis of the two years of the ECMWF data (not show).

The results shown in Fig. 2 clearly reveal that local effects are fundamental to determine the surface circulation in that Mediterranean Area. Considering the geographical position of the experimental site located at a flat coastal area close to the coastline with behind mountains, two main local effects could be important: breeze circulation and the channelling of air masses trough the Marcellinara gap (Fig. 1).

To quantify the role of the breeze circulation, we show the distributions of the wind direction and speed as a function of the hours of the day in Fig. 3a and b. The role of the breeze circulation is evident: during the day, winds blow from W-WSW while at the night they are mainly from NEENE. The presence of the 270 and 180 sector winds during night are likely tied to the large-scale westerly winds and to the Scirocco wind occurrence respectively. The onset of diurnal breeze circulation starts at about 10:00 and ends at 19:00 LST $(\mathrm{LST}=\mathrm{UTC}+1 \mathrm{~h})$. These values are modulated by the season (not shown): in summer the diurnal breeze starts at 08:00 and ends at 23:00 LST while in winter, the diurnal breeze blows from 12:00 to 18:00 LST. These conditions are typical of the breeze regime (Pearson, 1973, 1975; Pielke, 1974, 2002; Simpson, 1994). The directional analysis in Fig. 3 confirms that the differences between wind rose distributions at the surface and at $850 \mathrm{hPa}$ are due to the breeze circulation.

\subsection{Seasonal surface wind distribution}

To gain a deeper knowledge of the local circulation, we show, in Fig. 4a, b, c, and d, the wind seasonal distribution recorded at the surface. We define seasons as following, winter (December, January and February); spring (March, April and May); summer (June, July and August) and fall (September,
October and November). In winter (Fig. 4a), wind comes mainly from NE-ENE (45\% compared to $34 \%$ in Fig. 2a) and the wind rose is more asymmetrical compared to the average conditions. Wind speed, as expected, is larger than average and it is greater than $6 \mathrm{~ms}^{-1}$ in more than $13 \%$ of occasions (10\% in Fig. 2a). Of all seasons, spring has the most symmetrical distribution of cases with respect to land and sea breeze i.e. W-WSW (42\%) and NE-ENE (34\%). For 2007-2008, we found that spring winds have the largest frequency of high wind speed (more than $17 \%$ of speed occurrence greater than $6 \mathrm{~ms}^{-1}$ ). This result is unexpected and it might be the result of the shorter period with respect to the analyses from Colacino (1990), Colacino et al. (1997), and Bolle (2003); in these papers it was found that the climate of the Central Mediterranean, which is typical of Calabria, is characterized by windier conditions in winter compared to other seasons.

During summer, wind blows $66 \%$ of the occurrences from the sector W-WSW; this value is about twice the average conditions (Fig. 2a). The frequency of high winds is the lowest: only $3 \%$ of occurrences are greater than $6 \mathrm{~ms}^{-1}$. The fall wind distribution is similar to the distribution in winter; winds mainly blow from the NE and ENE directions with $44 \%$ of the occurrences. Similarly to average conditions (Fig. 2a) about $35 \%$ of occurrences are from W-WSW and $8 \%$ of velocities are larger than $6 \mathrm{~ms}^{-1}$.

Despite the rather symmetric distribution of winds, the seasonal distributions show, on average, preferential directions at the experimental site. In particular, summer circulations are mainly from W-WSW while during fall and winter directions are mainly from the NE-ENE sector.

\subsection{Pressure and temperature daily variation}

To further investigate the differences of the wind speed distribution according to season, we addressed the daily variation of the pressure and temperature fields in terms of differences $\Delta P$ and $\Delta T$ of their values between two consecutive hours defined as

$\Delta P=P_{i+1}-P_{i} \quad$ and $\quad \Delta T=T_{i+1}-T_{i}$

where $i=0,23$ indicates the hour, during summer and winter.

We refer to the results showed in Simpson (1994) where, the daily variation of the pressure pattern is estimated by the difference between the mean pressure during the day and the hourly values.

In Fig. 5, we compare the hourly pressure variation in winter and summer during the day. During summer night, $\Delta P$ is small with values around 0; after sunrise it becomes mostly negative reaching its maximum absolute value at 09:00 LST. This maximum is correlated to the highest value of $\Delta T$ (not shown) and is representative of the time when the diurnal breeze fully develops. The $\Delta P$ decreases during the day and reverts its sign reaching its positive maximum at around 20:00 LST. The maximum value of $\Delta P$ is representative of 
(a)

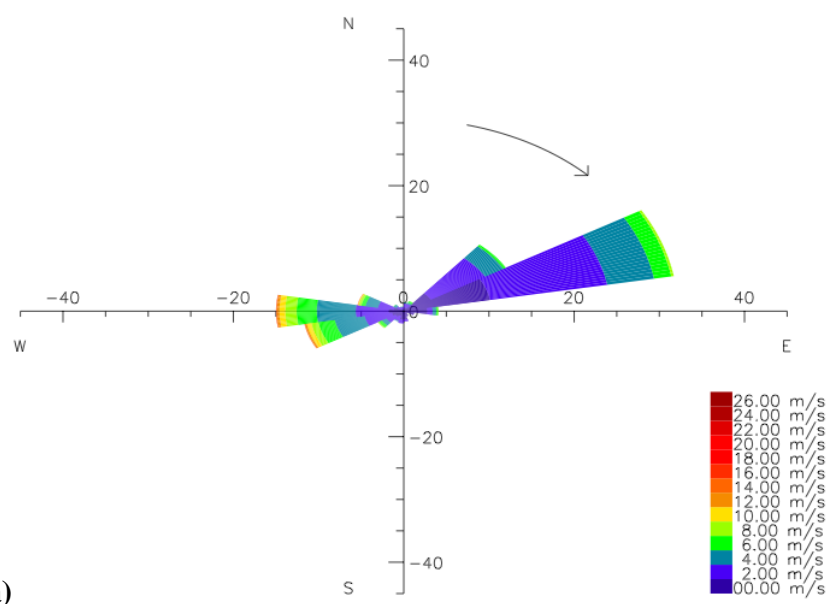

(c)

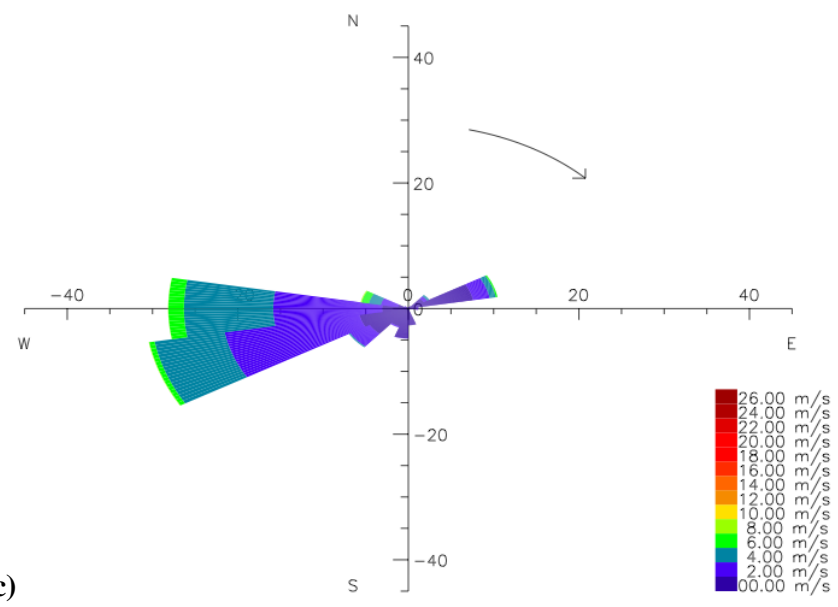

(b)

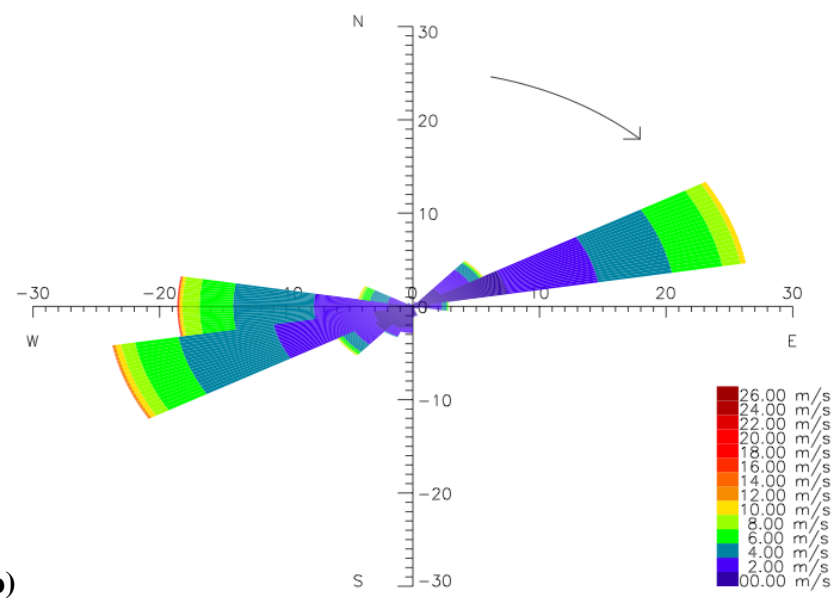

(d)

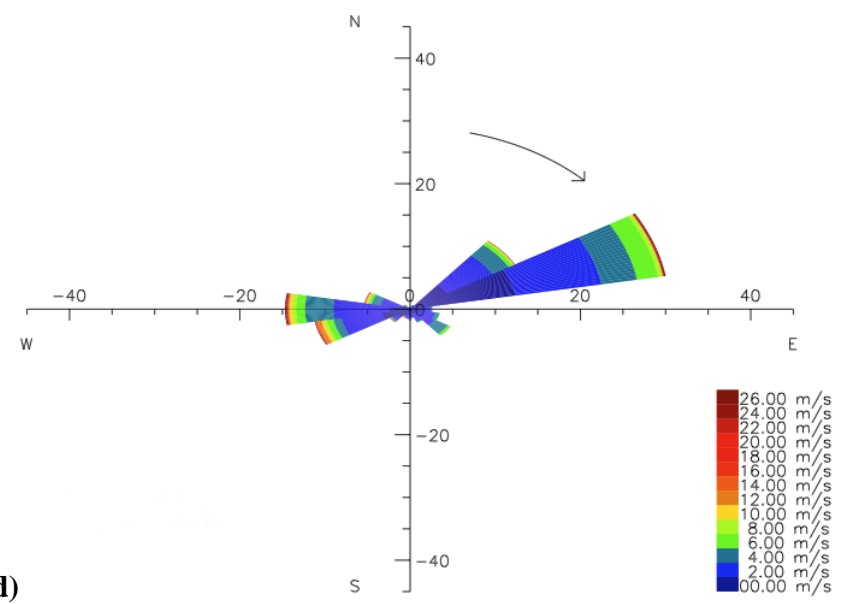

Figure 4. Wind rose recorded at the surface station for the period 2007-2008 for (a) winter, (b) spring, (c) summer, and (d) fall. As in Fig. 2a. Colour scale shows the wind intensity $\left(\mathrm{ms}^{-1}\right)$.

the time when the diurnal breeze forcing stops. It should be noticed that the time when the pressure forcing stops does not coincide with a reversal of the breeze circulation because of the inertia of the circulation. In particular we found that in summer the pressure forcing for the diurnal breeze stops on average at 20:00 LST while the diurnal circulation blows until 23:00 LST (see the comment of Fig. 3a and b of the previous section).

In winter the absolute value of $\Delta P$ is lower and varies less than in summer, because of the decreased solar heating. Moreover the time of the minimum (maximum) value of $\Delta P$ is delayed (anticipated), compared to summer, as a consequence of the delayed and shorter solar heating.

In Fig. 6, we compare the correlation between $\Delta P$ and $\Delta T$ in winter and summer. We note that only during summer $\Delta P$ and $\Delta T$ appear to be correlated showing that the hourly pressure variation in summer, is mainly driven by the solar radiation. In winter other factors, as the large scale forcing, likely play an important role.

\subsection{The role of SST and large-scale flow on the seasonal distributions of breezes}

In this section, we investigate the role of two main physical factors that could cause the differences in seasonal wind distributions: the sea-land temperature difference and the synoptic circulation in the Mediterranean area.

Figure 7 shows the monthly average of the difference $\Delta T$ between the SST ( $\left.T_{\text {sea }}\right)$ in the S. Eufemia Gulf and the surface temperature $T_{\text {land }}$ recorded at the experimental site between 11:00 and 16:00 LST (diurnal breeze) and between 00:00 and 06:00 LST (nocturnal breeze). These time windows were selected because they include the maximum speed of the diurnal and nocturnal breeze circulation, respectively, so they are suitable to characterize the thermal contrast between the sea surface and land for the two branches of breeze circulation. The $\Delta T$ of the diurnal breeze is negative, i.e. the sea is colder that the land, on average, from March to October, while it decreases from November and is positive for the whole winter. This does not exclude that, on particular days, diurnal 

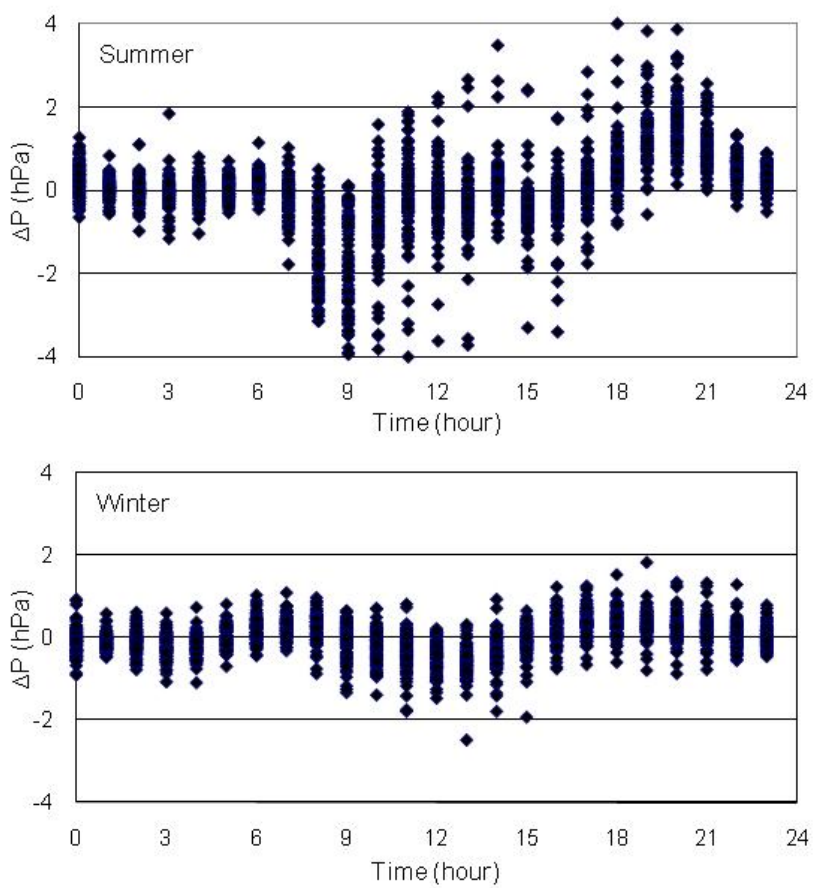

Figure 5. (Top) hourly $\Delta P$ during summer. (Bottom) hourly $\Delta P$ during winter.
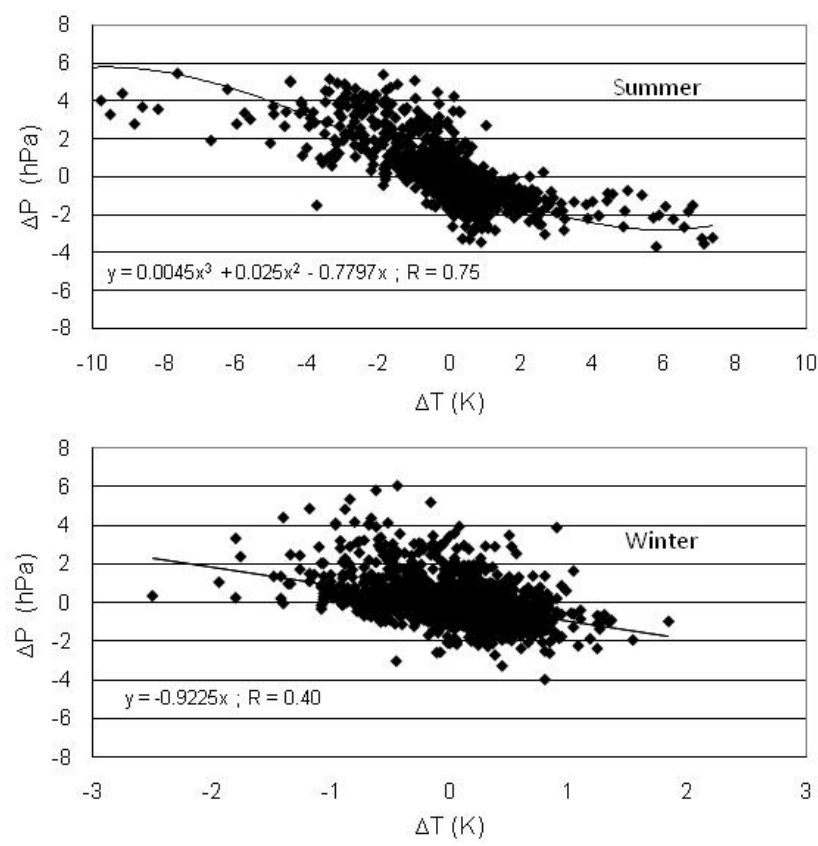

Figure 6. (Top) hourly $\Delta P$ versus $\Delta T$ during summer. (Bottom) hourly $\Delta P$ versus $\Delta T$ during winter. We note that during winter the $\Delta P$ and $\Delta T$ hourly variations appear less correlated than during summer.

breeze develops in November and during winter, and nevertheless sea breeze plays a minor role. The largest absolute difference of the diurnal sea-land temperature i.e. $\Delta T=4{ }^{\circ} \mathrm{C}$ occurs during the whole summer period.

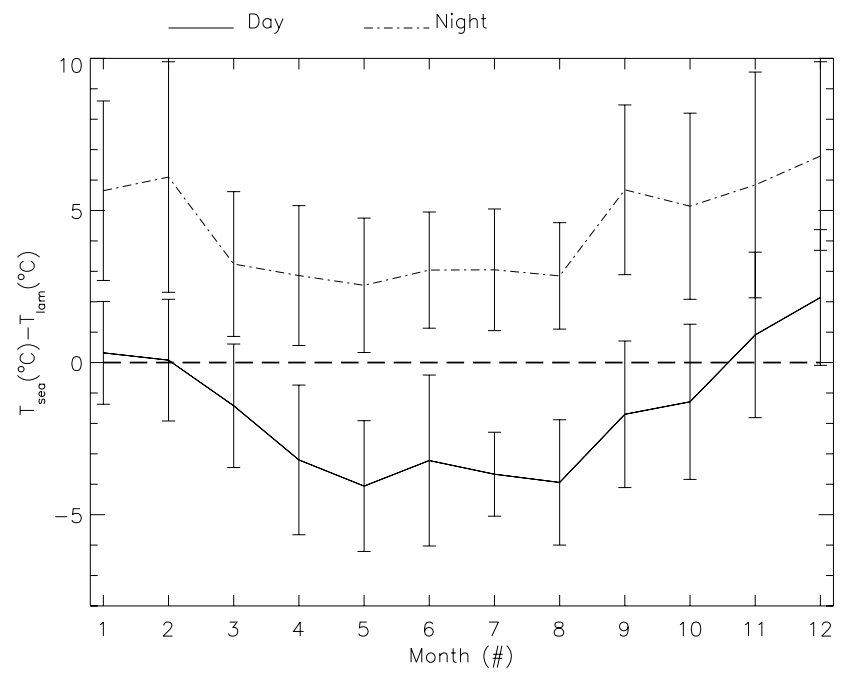

Figure 7. Monthly mean of the difference between the SST of the St. Eufemia Gulf and the air temperature measured at the station during 2007-2008. Solid curve represents the temperature difference from 11:00 to 16:00 LST; dot-dash line represents the temperature difference from 00:00 to 06:00 LST. Error bars are two times the monthly standard deviation of the temperature difference.

The monthly average of $\Delta T$ for the nocturnal breeze (00:00-06:00 LST) is always positive, i.e. the sea surface is always warmer than the land surface indicating that the nocturnal breeze can develop in all seasons. However, Fig. 7 shows that $\Delta T$ during winter and fall is twice that of spring and summer $\left(6^{\circ} \mathrm{C}\right.$ and $3{ }^{\circ} \mathrm{C}$ respectively) and that nocturnal breeze is expected to be important in the former seasons because $\Delta T=6^{\circ} \mathrm{C}$ is the maximum absolute surface temperature difference between the sea and the land.

It is not trivial to exactly quantify the impact of the largescale flow and the air channelling through the Marcellinara gap because circulations are the result of the superposition of the wind channelling and the breeze. Nevertheless, evidence can be found by studying the $850 \mathrm{hPa}$ wind distribution from the ECMWF analysis for 2007-2008. To minimize the influence of topography on wind distributions, we considered two ECMWF analysis grid points, i.e. (15.5 E, 39 N) and $(17 \mathrm{E}, 38.5 \mathrm{~N})$ : the former point located over the Tyrrhenian Sea in front of Lamezia Terme and the latter located over the Ionian Sea, near the east-side entrance of the Marcellinara gap (Fig. 1). The first grid point is used to evaluate the frequency of winds whose direction is between $210^{\circ}$ and $330^{\circ}(\mathrm{NNW} / \mathrm{SSW})$, the second for winds whose direction is between $30^{\circ}$ and $150^{\circ}$ (NNE/SSE). It should be noticed that results are not very sensitive to the exact grid point choice. We tried several grid points over land and over the sea, bilinear interpolation to both entrances of the Marcellinara gap and inside the gap, and the same grid points at $700 \mathrm{hPa}$ obtaining similar results. 
Table 2. Seasonal wind occurrences $f(\%)$ for 2007-2008, from the ECMWF analysis at $850 \mathrm{hPa}$. Second and fourth columns are for grid point $(15.5 \mathrm{E}, 39 \mathrm{~N})$, third and fifth columns are for grid point $(17 \mathrm{E}, 38.5 \mathrm{~N})$.

\begin{tabular}{|c|c|c|c|c|}
\hline Season & $\begin{array}{c}f(\%) \\
(15.5 \mathrm{E}, 39 \mathrm{~N}) \\
210<\operatorname{dir}<330 \\
U>8 \mathrm{~ms}^{-1}\end{array}$ & $\begin{array}{c}f(\%) \\
(17 \mathrm{E}, 38.5 \mathrm{~N}) \\
30<\operatorname{dir}<160 \\
U>8 \mathrm{~ms}^{-1}\end{array}$ & $\begin{array}{c}f(\%) \\
(15.5 \mathrm{E}, 39 \mathrm{~N}) \\
210<\operatorname{dir}<330 \\
U>8 \mathrm{~ms}^{-1}\end{array}$ & $\begin{array}{c}f(\%) \\
(17 \mathrm{E}, 38.5 \mathrm{~N}) \\
30<\operatorname{dir}<160 \\
U>8 \mathrm{~ms}^{-1}\end{array}$ \\
\hline Winter & 24 & 4 & 28 & 5 \\
\hline Spring & 30 & 7 & 35 & 10 \\
\hline Summer & 23 & 2 & 29 & 4 \\
\hline Fall & 23 & 2 & 29 & 4 \\
\hline
\end{tabular}

Table 2 shows the wind occurrence for wind speeds larger than $8 \mathrm{~ms}^{-1}$ at $850 \mathrm{hPa}$, which should have a major effect on breeze circulation (Lyons, 1972). Using observational data, Lyons (1972) developed an index to estimate whether a lake breeze would occur. Results show that when the ratio $V^{2} / \Delta T$ (where $V$ is the geostrophic wind speed $\left(\mathrm{ms}^{-1}\right)$ ) is greater than 10 the breeze will not occur. The breeze will not develop because the horizontal pressure gradient generated by the differential heating between the land and the sea is not enough to overcome the kinetic energy of the large-scale flow. The maximum $\Delta T$ for Lamezia Terme is $6{ }^{\circ} \mathrm{C}$ in fall, accordingly, $8 \mathrm{~ms}^{-1}$ of large-scale wind should suppress the breeze development.

In Table 2, it results that occurrence of $U>8 \mathrm{~ms}^{-1}$ is $23-30 \%$ for winds from the NNW-SSW sector, confirming that the westerlies are more frequent than other directions (Fig. 2b). Spring has the largest occurrence (30\% compared to $23-24 \%$ of other seasons). The occurrence of winds from NNW-SSW is channelled in the W-WSW directions by the Marcellinara gap.

Table 2 and Fig. 2b show that frequency of winds from the NNE-SSE sector is much lower than for the sector NNW/SSW being 2\%, 2\%, $4 \%$ and $7 \%$ for summer and fall, winter and spring respectively.

We also compted the wind occurrence for wind speed larger than $6 \mathrm{~ms}^{-1}$ at $850 \mathrm{hPa}$ to consider a more populated statistic. Results are similar to the $8 \mathrm{~ms}^{-1}$ threshold: westerlies are much more frequent than easterlies, spring has the largest occurrence of high wind speeds (both easterlies and westerlies), and easterlies are infrequent in summer, fall and winter.

Fall occurrence of large-scale winds from NNE-SSE is rather low, implying that winds from NE-ENE in Lamezia Terme are the result of katabatic winds that merge with the land breeze to form the nocturnal breeze. Winter flow from NE-ENE is also due in large part to the nocturnal breeze land/mountain breezes because the synoptic wind from this direction is only $1-2 \%$ more frequent than in fall.

The symmetry of the wind distribution during spring with respect to the other seasons can be explained by two factors:
- The largest influence of the large-scale forcing (7\% for $8 \mathrm{~ms}^{-1}, 10 \%$ for $6 \mathrm{~ms}^{-1}$ ) from east, compared to the other seasons, which enhances the circulations from NE-ENE at of $4-5 \%$ and then might contrast the development of the sea breeze; and

- The progressive increasing of the mean daytime $\Delta T$ from March to June. During March, the mean sea-land temperature difference is the lowest i.e. $\Delta T=1.5^{\circ} \mathrm{C}$; therefore this synoptic situation would not favour the sea breeze development. On the other hand, during June, the high $\Delta T=4{ }^{\circ} \mathrm{C}$ would instead favour the development of the sea breeze contributing to the westerly flow occurrence.

\section{Conclusions}

From the combined analysis of the large-scale flow and surface in-situ and remote measurements, we can derive few general conclusions on the local circulation at Lamezia Terme:

a) The diurnal breeze circulation in spring, summer and part of fall is a superposition of the large-scale and local-scale flow.

b) The large-scale forcing usually acts in phase with the diurnal breeze and opposes the nocturnal wind development.

c) The large-scale forcing mainly drives the diurnal circulation from November and in winter.

d) The nocturnal flow is mostly due to the nocturnal breeze circulation.

While a subjective examination of each day and the account of more meteorological parameters (cloud coverage, global radiation, synoptic-scale pattern of the day etc.) should produce a finer classification of the impact of large-scale and local-scale on the daily circulation at Lamezia Terme, this 
analysis is out of the scope of the present paper. Nevertheless, previous results on both SST and large-scale flow clarify several aspects of wind rose of Fig. 4. In particular:

a) In summer, the daytime difference between the land surface temperature and the SST reaches its maximum (about $4^{\circ} \mathrm{C}$ ), while the nighttime difference reaches its minimum (absolute value $3{ }^{\circ} \mathrm{C}$ ). This causes strong and frequent diurnal circulations while the nocturnal breeze is weak. The nocturnal breeze direction is opposite to the large-scale winds, which suppress its occurrence; the diurnal breeze and the large-scale winds merging causes intense diurnal flows. These factors explain the asymmetry of the wind rose in Fig. 4c.

b) In winter and fall the nocturnal difference between the sea and land surface temperature reaches a maximum $\left(6{ }^{\circ} \mathrm{C}\right)$ while diurnal difference is at minimum (especially in winter). This causes strong, frequent and intense nocturnal breeze despite of the large-scale forcing that is usually opposed to local-scale flow.

c) In our definition of spring, the absolute difference between the land surface temperature and the SST during the day is varying with months: from $1.5^{\circ} \mathrm{C}$ in March to $4^{\circ} \mathrm{C}$ in May. This variation is likely to cause the symmetry of the distribution among westerlies and easterlies. During March the wind distribution resemble the distribution in winter and fall. During May it will have the predominant westerly shape characteristics of the summer distribution.

Work in progress addresses the turbulent characteristics of the atmospheric PBL at a coastal area in different meteorological condition. The data will be analyzed considering the temperature difference between sea and land as it is an important factor to take into account for further classifying the coastal regimes.

Acknowledgements. This work was partially funded by the project "ALPI: ALlerta Precoce Incendi boschivi" funded by the Calabria Region. We are grateful to OSI SAF and EUMETSAT for Sea Surface Temperature data. We are grateful to ECMWF and Italian Air Force for the access to MARS data (Meteorological Archive and Retrieval System).

Edited by: M. M. Miglietta

Reviewed by: I. Koletsis and another anonymous referee

\section{References}

Abe, S. and Yoshida, T.: The effect of the width of a peninsula to the sea breeze, J. Meteorol. Soc. Jpn., 60, 1074-1084, 1982.

Bolle, H. J.: Mediterranean climate - variability and trends, Springer-Verlag, Berlin, 2003.

Caccia, J.-L., Guénard, V., Benech, B., Campistron, B., and Drobinski, P.: Vertical velocity and turbulence aspects during Mistral events as observed by UHF wind profilers, Ann. Geophys., 22, 3927-3936, 2004, http://www.ann-geophys.net/22/3927/2004/.

Conte, M., Giuffrida, A., and Tedesco, S.: The Mediterranean Oscillation, in: Impact on precipitation and hydrology in Italy Climate Water, Publications of the Academy of Finland, Helsinki, 121-127, 1989.

Colacino, M.: Mediterranean Meteorology, Proceedings NATOASI, edited by: Charnock, H., Reports in Meteorology and Oceanography, 40, 1-38, 1990.

Colacino, M., Conte, M., and Piervitali, E.: Elementi di climatologia della Calabria, IFA-CNR, Rome, 197 pp., 1997.

Defant, F: Local winds, Compendium of Meteorology, edited by: Maloney, T. F., American Meteorological Society, Boston, 1951.

De Leo, L., Federico, S., Sempreviva, A. M., Pasqualoni, L., Avolio, E., and Bellecci, C.: Study of the development of the sea breeze and its micro-scale structure at a coastal site using a Multi-Tone Sodar system, Earth Environmental Science, 1, 1-9, doi:10.1088/1755-1307/1/1/012054, 2008.

Doran, E.: Objective analysis of mesoscale flow fields in Israel and trajectory calculations, Israel J. Earth Sci., 28, 33-41, 1979.

Federico, S., Dalu, G. A., Bellecci, C., and Colacino, M.: Mesoscale energetics and flows induced by sea-land and mountain-valley contrasts, Ann. Geophys., 18, 235-246, 2000, http://www.ann-geophys.net/18/235/2000/.

Federico, S., Bellecci, C., and Colacino, M.: Atmospheric convergente diabatically generated in the CBL over a mountainous peninsula, Nuovo Cimento C, 24C, 223-243, 2003.

Federico, S., Avolio, E., Pasqualoni, L., De Leo, L., Sempreviva, A. M., and Bellecci, C.: Preliminary results of a 30-year daily rainfall data base in southern Italy, Atmos. Res., 94(4), 641-651, doi:10.1016/j.atmosres.2009.03.008, 2009.

Kallos, G., Kassomenos, G. P., and Pielke, R. A.: Synoptic and mesoscale weather conditions during air pollution episodes in Athens, Greece, Bound.-Lay. Meteorol., 62, 163-184, 1993.

Lyons, W. A.: The climatology and prediction of the Chicago lake breeze, J. Appl. Meteorol., 11, 1259-1270, 1972.

Mastrantonio, G., Petenko, I. , Viola, A., Argentini, S., Coniglio, L., Monti, P., and Leuzzi, G.: Influence of the synoptic circulation on the local wind field in a coastal area of the Tyrrhenian Sea, Earth Environ. Sci., 1, 1-9, doi:10.1088/1755-1315/1/1/012049, 2008.

O\&SI SAF: High Latitude SST product manual, version 1.2, 10/10/2002 Met.no, Oslo (Norway), http://saf.met.no/docs/ss2 pmhlsst_v1p2.pdf (last access: 23 April 2010), 2006.

Pearson, R. A.: Properties of the sea breeze front as shown by a numerical model, J. Atmos. Sci., 30, 1050-1060, 1973.

Pearson, R. A.: On the asymmetry of the land breeze sea breeze circulation, Q. J. Roy. Meteor. Soc., 101, 529-536, 1975. 
Pielke, R. A.: A three-dimensional numerical model of the sea breeze over south Florida, Mon. Weather Rev., 102, 115-139, 1974.

Pielke, R. A.: Mesoscale Meteorological Modeling, Academic Press, San Diego, 2002.

Piervitali, E., Colacino, M., and Conte, M.: Rainfall over the central-western Mediterranean Basin in the period 1951-1995. Part I: Precipitation trends, Nuovo Cimento, C, 21, 331-344, 1999.

Simpson, J. E.: Sea breeze and local winds, Cambridge University Press, Cambridge, 224 pp., 1994.
Trigo, I. F., Davies, T. D., and Grant, R. B.: Objective Climatology of Cyclones in the Mediterranean Region, J. Climate, 12, 16851686, 1999.

Trigo, I. F., Grant, R. B., and Davies, T. D.: Climatology of Cyclogenesis Mechanisms in the Mediterranean, Mon. Weather Rev., 130, 549-569, 2002.

Uppala, S. M., Kallberg, P. W., and Simmons, A. J.: The ERA-40 re-analysis, Q. J. Roy. Meteor. Soc., 131, 2961-3012, 2005. 